\title{
Structural evolution, electrical and optical properties of AZO films deposited by sputtering ultra-high density target
}

\author{
JIWEN XU ${ }^{1,2}$, ZUPEI YANG ${ }^{1, *}$, HUA WANG ${ }^{2}$ and XIAOWEN ZHANG ${ }^{2}$ \\ ${ }^{1}$ School of Material Science and Engineering, Shaanxi Normal University, Xi'an 710062, China \\ ${ }^{2}$ School of Material Science and Engineering, Guilin University of Electronic Technology, Guilin 541004, China
}

MS received 10 September 2013; revised 24 October 2013

\begin{abstract}
Aluminum-doped zinc oxide (AZO) target was fabricated using AZO nanopowders synthesized by co-precipitation method and then the AZO films with different thicknesses were deposited on glass by d.c. magnetron sputtering at room temperature. AZO target is nodules free and shows homogeneous microstructure, ultra-high density and low resistivity. $\mathrm{ZnAl}_{2} \mathrm{O}_{4}$ phase appears in $\mathrm{AZO}$ target and disappears in AZO films. All AZO films show $c$-axis preferred orientation and hexagonal structure. With increasing film thickness from 153 to $1404 \mathrm{~nm}$, the crystallinity was improved and the angle of (002) peak was close to $34 \cdot 45^{\circ}$. The increase in grain size and surface roughness is due to the increase in film thickness. The decrease of resistivity is ascribed to the increases of carrier concentration and Hall mobility. The lowest resistivity is $9.6 \times 10^{-4} \Omega \cdot \mathbf{c m}$. The average transmittance of AZO films exceeds $80 \%$, and a sharp fundamental absorption edge with red-shifting is observed in the visible range. The bandgap decreases from 3.26 to $3.02 \mathrm{eV}$.
\end{abstract}

Keywords. AZO film; ultra-high density; ceramic target; nanopowders; evolution.

\section{Introduction}

Transparent conducting oxide (TCO) films such as Sn-doped $\mathrm{In}_{2} \mathrm{O}_{3}$ (ITO), Al- or Ga-doped $\mathrm{ZnO}$ (AZO or GZO) and F-doped $\mathrm{SnO}_{2}$ (FTO) have high conductivity and transmittance and have been heavily studied for their applications in light-emitting diodes, organic lightemitting diodes, liquid crystal displays, touch panels and thin film solar cells (Katayama 1999; Klutha et al 1999; Kima et al 2001; Taka et al 2002; Lei et al 2010; Park et al 2011). For TCO films fabrication, magnetron sputtering is a mature technology, because of low growth temperature, high growth rate, high quality and easy for large area coating (Swann 1998). Therefore, the alloy or ceramic targets become the key material required. Alloy target used for AZO films is more sensitive to minor changes of sputtering parameters (e.g. oxygen partial pressure or flow rate) (Kawada 1990). Ceramic target instead of alloy target can resolve the above unstable problem. However, the arcing and nodules formation on the target surface near or sometimes in the erosion racetracks (Ishibashi et al 1990; Omata et al 2006) weakens the advantages of ceramic target. The formation of nodules results in reducing growth rate and particulate contamination which degenerates film quality. The coating system has to be shut down frequently for cleaning

*Author for correspondence (yangzp@snnu.edu.cn) nodules. Formation of nodules on target surface is therefore highly undesirable. The most important way to reduce nodules is to increase the target density and decrease the composition inhomogeneous distribution (Nadaud et al 1994; Nakashima and Kumahara 2002).

AZO films were deposited mainly using AZO ceramic target in recent studies. To optimize performance of AZO films, such as resistivity, transmittance and texture surface, many researchers (Dewald et al 2009; Li et al 2009; Hsu et al 2010) focussed on the influences of sputtering parameters, such as doping elements and concentration, growth temperature, power, pressure, atmosphere, power supply, annealing and buffer layer. However, how to prepare high-quality target and the correlation between target and film are rarely focussed, which have prevented the optimization of AZO film.

In the present paper, AZO films have been mainly used in CIGS and Si thin film solar cells as transparent and conductive front contact layer because of their cheap and abundant raw materials as well as excellent electrical and optical properties (Kaelin et al 2004; Tark et al 2011). If the thickness of AZO film can be thinned and the conductivity is not be reduced, which not only benefits materials saving, but also decreases light absorption.

In this work, ultra-high density AZO target was fabricated using high sintering activity powders. The effects of thickness on the structural evolution, electrical and optical properties of AZO films prepared by ultra-high density target were investigated. 


\section{Experimental}

AZO powders were prepared by co-precipitation method using the aqueous solution of $\mathrm{Zn}\left(\mathrm{NO}_{3}\right)_{2} \cdot 6 \mathrm{H}_{2} \mathrm{O}$ and $\mathrm{Al}\left(\mathrm{NO}_{3}\right)_{3} \cdot 9 \mathrm{H}_{2} \mathrm{O}$ with 5 at\% doping ( $\mathrm{Al} / \mathrm{Zn}$ atomic ratio). After preparing $0.2 \mathrm{~mol} / \mathrm{L}\left(\mathrm{Zn}^{2+}\right.$ ion concentration) aqueous solution, $3 \mathrm{~mol} / \mathrm{L}$ ammonia was then slowly dropped to the aqueous solution under vigorous stirring until $\mathrm{pH}$ value reached 8 . The precipitate was washed using distilled water to remove $\mathrm{NO}_{3}^{-}$ions and then dispersed with ethanol. AZO powders were obtained by calcining the precipitates at $600{ }^{\circ} \mathrm{C}$ for $2 \mathrm{~h}$. The green body was pressed and compacted by cold isostatic pressing (250 MPa). AZO target was sintered at $1400{ }^{\circ} \mathrm{C}$ for $4 \mathrm{~h}$ in air. For observing grain boundary and size, the target was thermally etched at $1200{ }^{\circ} \mathrm{C}$ for $1 \mathrm{~h}$ in air.

AZO films were deposited on glass substrate by d.c. magnetron sputtering at room temperature after $5 \mathrm{~min}$ pre-sputtering. The chamber base pressure was $8 \times$ $10^{-5} \mathrm{~Pa}$, the discharge gas was argon without introducing oxygen. The power was $100 \mathrm{~W}$ and working pressure was $1.5 \mathrm{~Pa}$. AZO films with thicknesses of 153, 414, 689 and $1404 \mathrm{~nm}$ were prepared by controlling sputtering time.

The grain size, surface and cross-section morphology were analysed by scanning electron microscope (SEM, JSM-5610LV, JEOL). The three-dimensional structure and roughness were observed by atomic force microscope (AFM, SPI3800N, Seiko). The composition was identified by energy-dispersive X-ray spectroscopy (EDS, Thermo NORAN vantage IV). The phase structure was characterized by X-ray diffraction (XRD, D8-ADVANCE, Bruker). The particle size distribution was measured by laser particle size analyser (Nanotrac TM150, Microtrac). The thickness was measured by profilometer (XP-Plus 100, Ambios). The resistivity, carrier concentration and mobility were measured by hall effect measurement system (HMS-3000, Ecopia) at room temperature. The visible transmittance was measured by spectrophotometer (VIS 723G, China).

\section{Results and discussion}

\subsection{Structure characteristics of AZO target}

Figure 1 shows particle morphology and size distribution of the as-synthesized AZO powders. The inset SEM image shows that the grain shape is quasi-spherical and particle size is about $85 \mathrm{~nm}$. However, the particle size distribution shows that the median diameter (D50) is $67 \mathrm{~nm}$ and the most particle size is smaller than $100 \mathrm{~nm}$. The particle size by SEM is larger than that by laser particle size analyser. This difference is ascribed to the weaker agglomerates among particles in the observed SEM powder. AZO nanopowders have high sintering activity, which can promote the densification of sintering body during sintering process. Figure 2 displays XRD patterns of the AZO powders and target and the inset shows surface image of the eroded target. XRD patterns indicate that the AZO powders and targets are polycrystalline and hexagonal structures. However, the diffraction peaks (marked with $\rightarrow$ ) originating from the $\mathrm{ZnAl}_{2} \mathrm{O}_{4}$ phase are also observed in figure 2. The phase content in AZO target is composed of $97 \% \mathrm{ZnO}$ (hexagonal) and $3 \% \mathrm{ZnAl}_{2} \mathrm{O}_{4}$ (cubic). $\mathrm{ZnAl}_{2} \mathrm{O}_{4}$ phase is insulator, which decreases conductivity of the AZO target. Since the solubility of the aluminum atoms in $\mathrm{ZnO}$ matrix is very small, the aluminum atoms easily react with $\mathrm{ZnO}$ to form the $\mathrm{ZnAl}_{2} \mathrm{O}_{4}$ phase during sintering process (Shirouzu et al 2007; Hélène et al 2009;

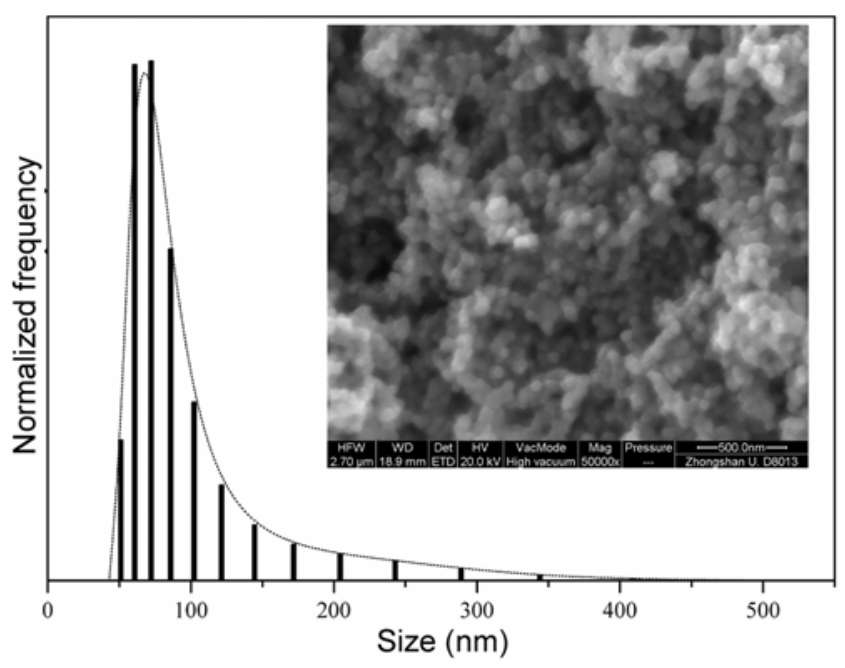

Figure 1. Particle morphology and size distribution of AZO powders.

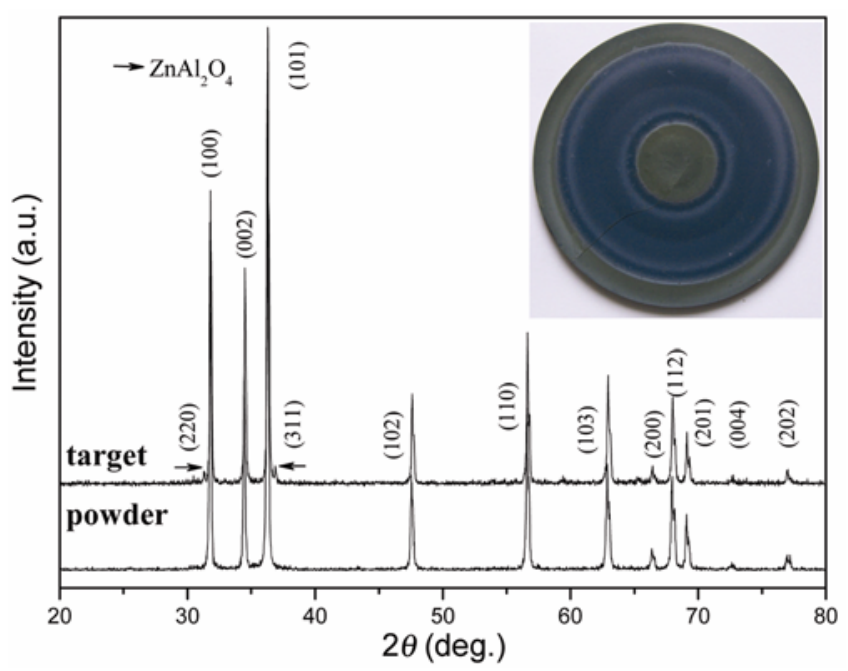

Figure 2. XRD patterns of AZO powders and target, and eroded target surface (inset). 
Zhang et al 2012). $\mathrm{ZnAl}_{2} \mathrm{O}_{4}$ phase is also observed in other fabrication processes such as hot pressing, hot isostatic pressing and slip casting (Long et al 2004; Sun et al 2009; Wang et al 2011). The inset shows that the target surface is nodule and particle free, which is due to the ultra-high density and low resistivity. The density is 99.3\% TD (theoretical density) and the resistivity is $2 \mathrm{~m} \Omega \cdot \mathrm{cm}$. The density and resistivity in this work are slightly better than the commercial target with a density of $>95-99 \%$ TD and resistivity of $<7 \mathrm{~m} \Omega \cdot \mathrm{cm}$ (Sittinger et al 2009).

AZO target sintered at $1400{ }^{\circ} \mathrm{C}$ exhibits dense structure with a few small pores as shown in figure 3. Spherical closed pores are entrapped primarily at the triple-grain points and the size of these pores is about $1 \mu \mathrm{m}$. However, the pores are invisible in grains. The $\mathrm{ZnO}$ grains are tightly packed and grain cleavage is invisible in the fracture surface as shown in figure 3(b). Figure 3 also clearly shows that the $\mathrm{ZnAl}_{2} \mathrm{O}_{4}$ phase (off-white regions) coexists with $\mathrm{ZnO}$ phase (dark regions) in the sintered body and the $\mathrm{ZnAl}_{2} \mathrm{O}_{4}$ phase homogeneously distribute in the $\mathrm{ZnO}$ matrix. The size of $\mathrm{ZnO}$ and $\mathrm{ZnAl}_{2} \mathrm{O}_{4}$ grains is
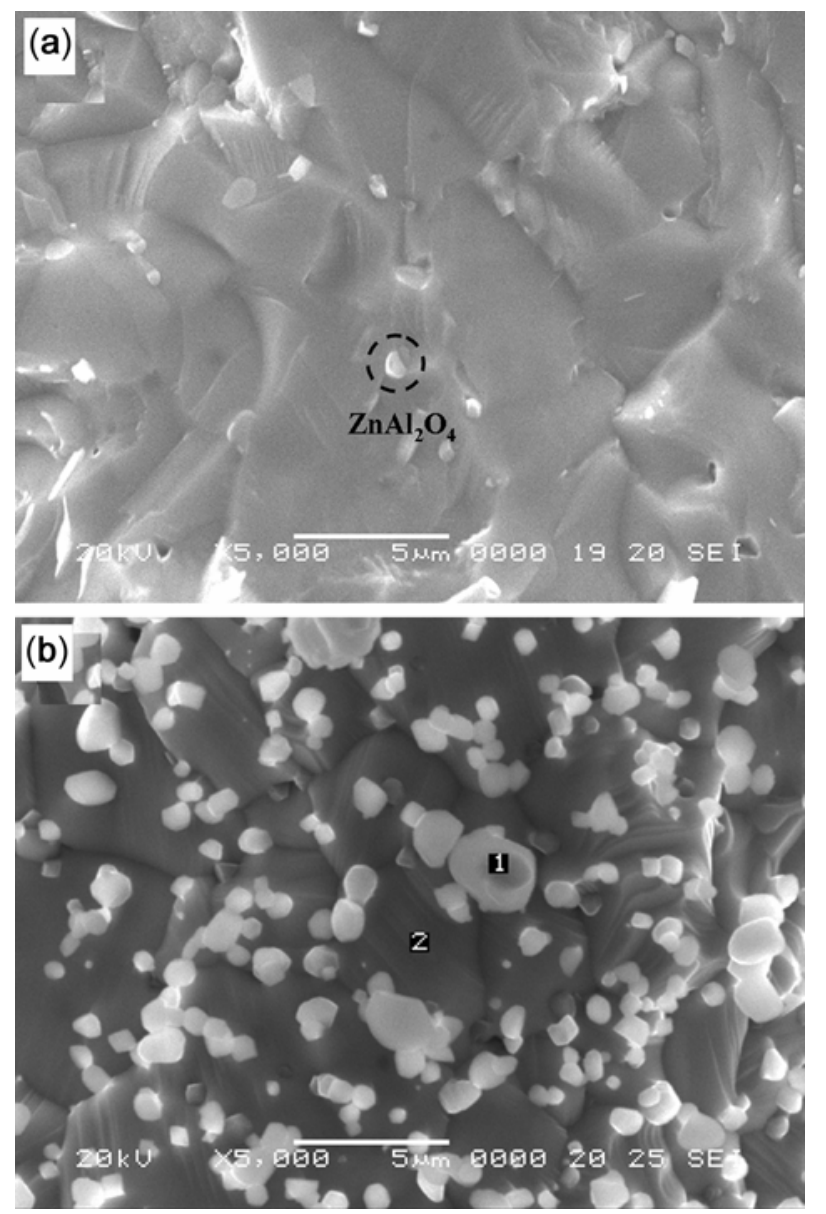

Figure 3. Fracture images of (a) as-prepared target and (b) thermally etched target at $1200{ }^{\circ} \mathrm{C}$ for $1 \mathrm{~h}$ in air. about 5 and $1 \mu \mathrm{m}$, respectively. The small grain size can improve sputtering rate and uniformity. $\mathrm{ZnO}$ and $\mathrm{ZnAl}_{2} \mathrm{O}_{4}$ phase in figure 3(b) are further confirmed by EDS as shown in figure 4 . It can be seen that the intensity of the $\mathrm{Al}$ energy peaks at spot 1 is stronger than that at spot 2. The aluminum and zinc atom contents at spot 1 are 24.5 at\% $\mathrm{Al}$ and 16 at\% $\mathrm{Zn}$ and the contents at spot 2 are 2.2 at\% $\mathrm{Al}$ and 46.1 at\% $\mathrm{Zn}$. The atomic ratio of $\mathrm{Al} / \mathrm{Zn}$ at spot 1 is close to the ratio of 2 in $\mathrm{ZnAl}_{2} \mathrm{O}_{4}$ phase and the ratio of $4.8 \%$ at spot 2 is close to 5 at\% doping level in the solution. These results indicate that the compositions at spots 1 and 2 are $\mathrm{ZnAl}_{2} \mathrm{O}_{4}$ and $\mathrm{ZnO}$ phases, respectively.

\subsection{Structure characteristics of AZO films}

Figure 5 displays XRD patterns of AZO films as a function of film thickness. Compared with the XRD patterns of AZO target, only (002) peaks exist in the XRD patterns for $\mathrm{AZO}$ films and no peaks of the $\mathrm{ZnAl}_{2} \mathrm{O}_{4}$ phase are observed. Therefore, AZO films show preferred orientation of $c$-axis perpendicular to the substrate surface. The $c$-axis preferred orientation can be elucidated by the 'grain boundary movement' model proposed by Lodder et al (1983). According to this model, at the very first stage of film growth, certain grains with a particular orientation start to grow. By thermodynamical coalescence of crystallites during film growth, oriented growth is achieved. The angle of (002) peak is smaller than the standard diffraction angle of $34.45^{\circ}$. This may be due to the ionization of $\mathrm{ZnO}$ or $\mathrm{Al}$ doping as reported by Kuroyanagi (1989) and Chun et al (2010). With increasing film thickness, the intensity of (002) peak increases and the angle gradually shifts to a high angle and is more close to the standard diffraction angle as shown in figure 5(b). The angle of (002) peak which is lower than the standard diffraction angle in this work is due to the residual tensile stress in AZO films rather than the ionization of $\mathrm{ZnO}$ or Al doping. Shifting towards high angle indicates that the (002) interplanar spacing $\left(d_{002}\right)$ becomes small and approaches to the $d_{002}$ of single crystal zinc oxide. Since the AZO films are deposited on amorphous glass substrate, large strain exists in AZO film because of lattice mismatch, which leads to the increase of $d_{002}$. The crystallinity of the thicker AZO film can be improved by deposition onto the former low crystalline layer. Hence, the stress in grain is reduced and $d_{002}$ decreases with increasing film thickness.

The surface morphology of AZO films as a function of film thickness and the cross-section morphology of the $1404 \mathrm{~nm}$ AZO film are shown in figure 6. It can be seen that the air side of AZO film is smooth on the entire surface. The cross-section morphology exhibits columnar structure perpendicular to the substrate. These columnar grains also indicate that the crystalline film is obtained on the amorphous glass substrate. Some small 


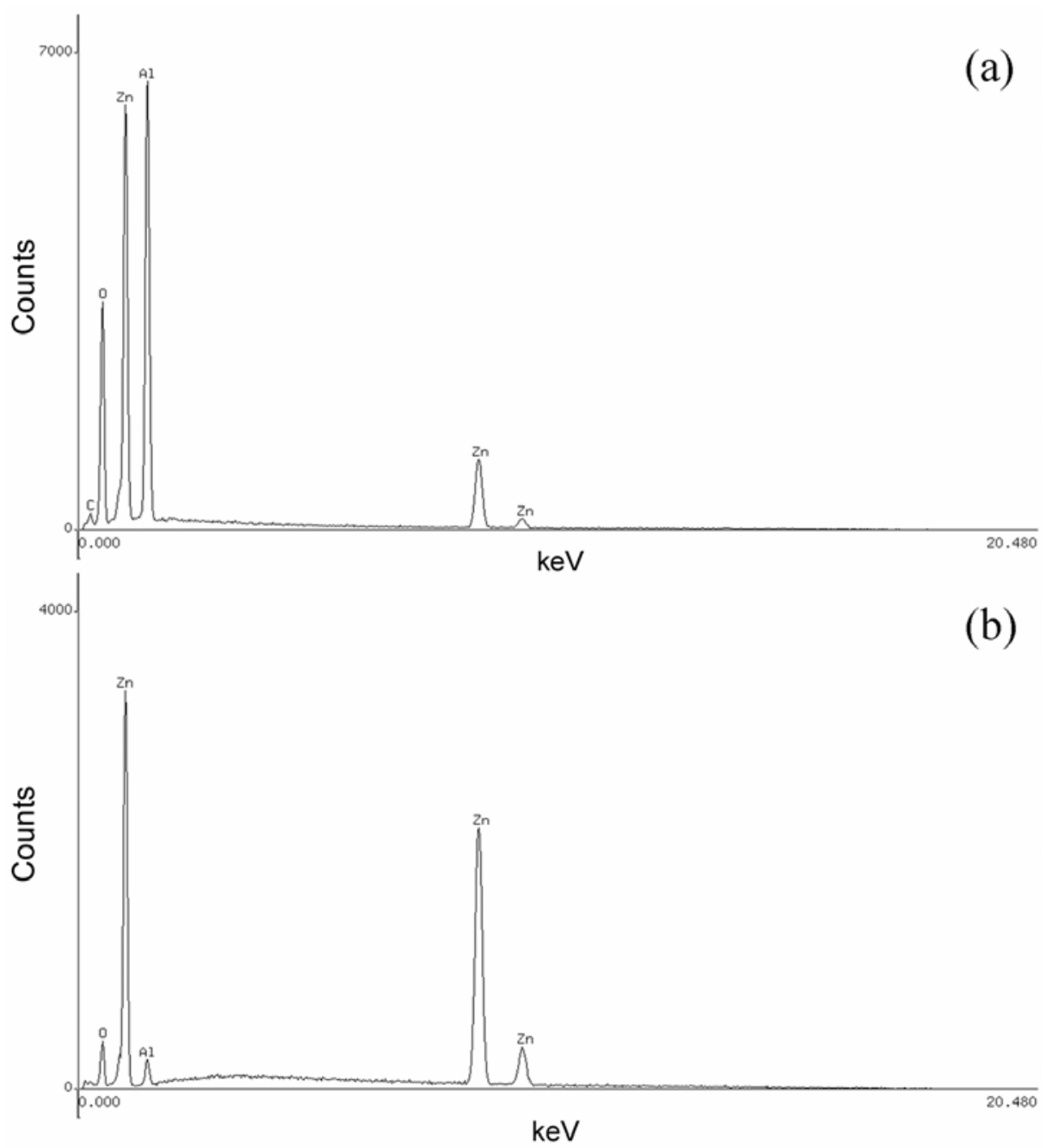

Figure 4. EDS spectra at (a) spot 1 and (b) spot 2 in figure 3(b).
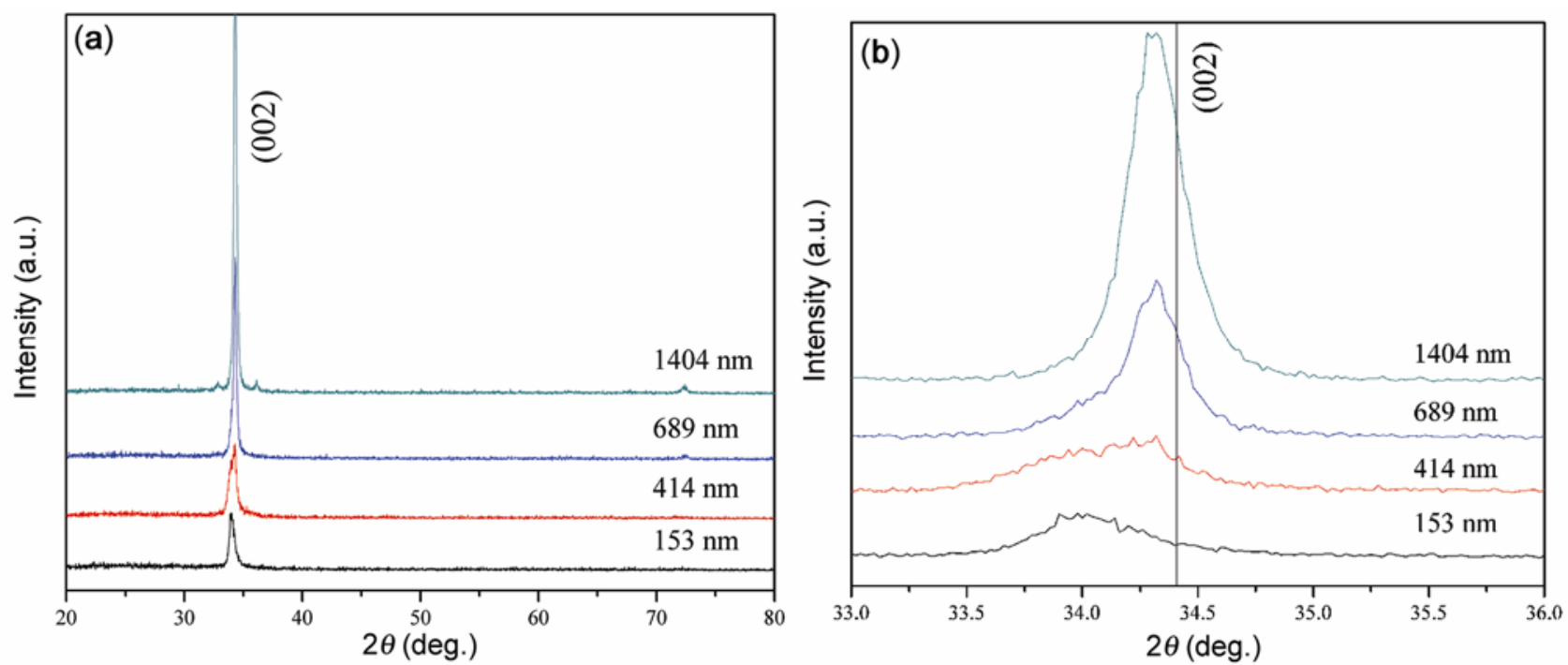

Figure 5. XRD patterns of AZO films at angle of (a) $20-80^{\circ}$ and (b) $33-36^{\circ}$. 
Structural evolution, electrical and optical properties of AZO films

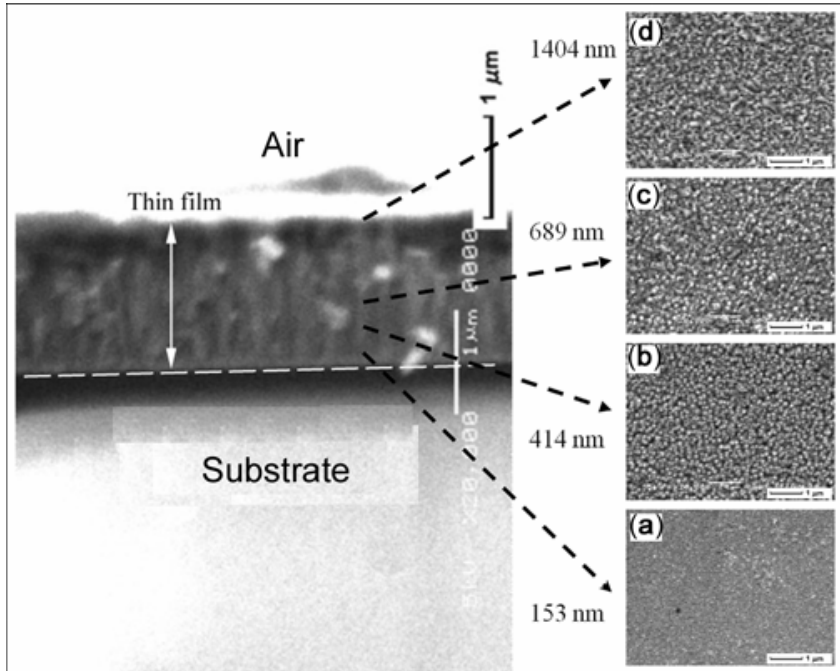

Figure 6. Cross-section morphology of the $1404 \mathrm{~nm}$ AZO film and surface morphology of AZO films with different thickness of (a) 153, (b) 414, (c) 689 and (d) $1404 \mathrm{~nm}$.
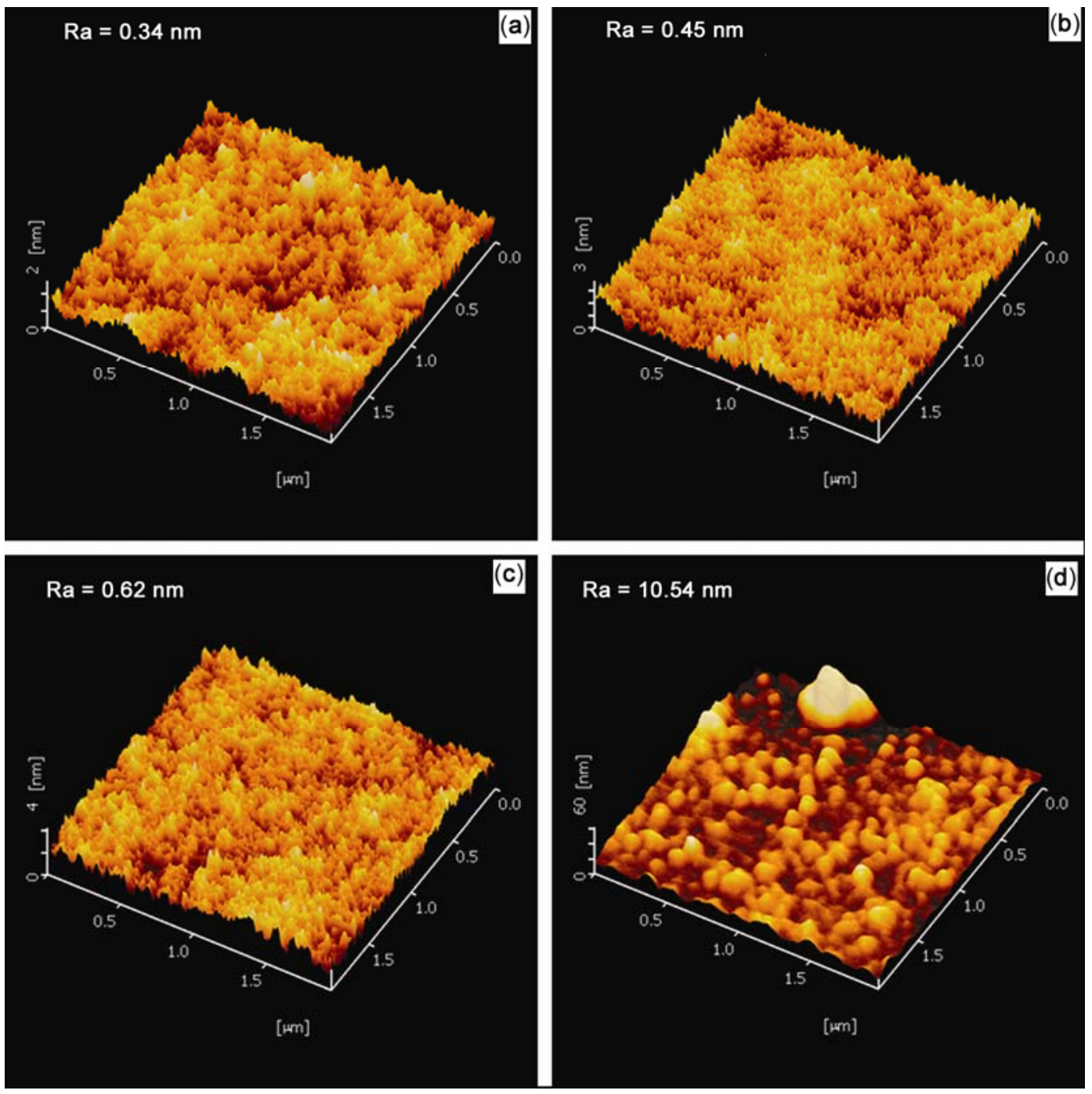

Figure 7. AFM images of AZO films with different thicknesses of (a) 153, (b) 414, (c) 689 and (d) $1404 \mathrm{~nm}$. 


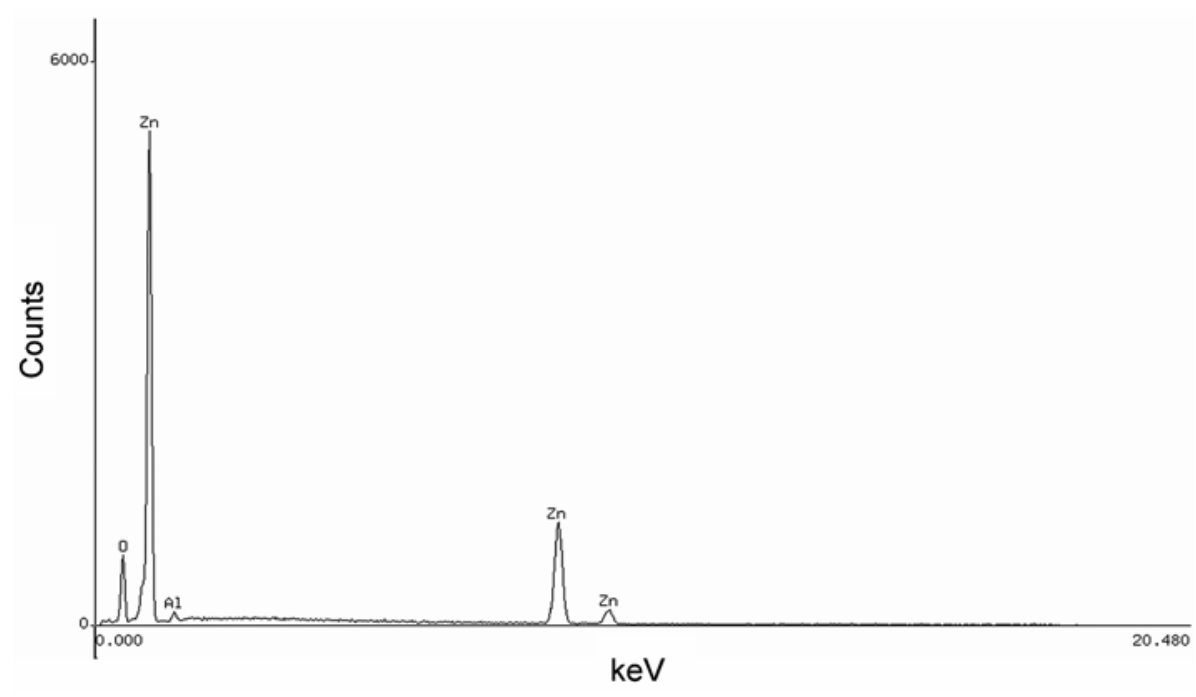

Figure 8. EDS spectrum of the $1404 \mathrm{~nm}$ AZO film.

grains are observed for the $153 \mathrm{~nm}$ AZO film. However, larger grains are observed for the 414, 689 and $1404 \mathrm{~nm}$ AZO films. The grain size of the $153 \mathrm{~nm} \mathrm{AZO} \mathrm{film} \mathrm{is}$ about $97 \mathrm{~nm}$. With increasing film thickness, the grain size increases to 127, 194 and $290 \mathrm{~nm}$, respectively. This suggests that the diffusion and transfer ability of surface atoms are improved with increasing film thickness, which leads to accelerated crystallization of AZO films and hence, the enhancement of grain size. The threedimensional surface structure and roughness is also investigated by AFM as shown in figure 7. It can be seen that the size of grain clusters increases with increasing film thickness. All AZO films show homogenous grains distribution with individual columnar grains extending upwards. In addition, the roughness increases from $0 \cdot 34$ to $10.54 \mathrm{~nm}$, when the film thickness increases from 153 to $1404 \mathrm{~nm}$. The increase of roughness with increasing film thickness mainly results from the corresponding change in grain size.

The elemental content of the $1404 \mathrm{~nm}$ AZO film is investigated by EDS as shown in figure 8. EDS results show that the $\mathrm{Zn}, \mathrm{Al}$ and $\mathrm{O}$ elements are present in $\mathrm{AZO}$ film. Si and Ca elements are not expected to be in the film and this may have resulted from the glass substrate. The data obtained by EDS illustrate that the 1.9 at\% $\mathrm{Al}$ and 45.7 at $\% \mathrm{Zn}$ in AZO film is close to the ratio of 4.8 at $\%$ in the AZO target.

\subsection{Electrical characteristics of AZO films}

Figure 9 shows resistivity $(\rho)$, carrier concentration $\left(n_{\mathrm{e}}\right)$ and Hall mobility $(\mu)$ as functions of film thickness. The resistivity is $5 \cdot 1 \times 10^{-3} \Omega \cdot \mathrm{cm}$ for the $153 \mathrm{~nm}$ AZO film and then it dramatically decreases to $9 \cdot 7 \times 10^{-4} \Omega \cdot \mathrm{cm}$ for the 1404 nm AZO film. Guilléna and Herrero (2010) and
Zhu et al (2012) reported similar relationship between thickness and resistivity with increasing thickness from 100 to $1100 \mathrm{~nm}$. The resistivity of $9.7 \times 10^{-4} \Omega \cdot \mathrm{cm}$ is inferior to $3.13 \times 10^{-4} \Omega \cdot \mathrm{cm}$ for AZO films deposited in $5 \% \mathrm{H}_{2}$ ambient reported by Zhu et al (2012). However, the lowest resistivity in our work is better than 1.6$2 \cdot 0 \times 10^{-3} \Omega \cdot \mathrm{cm}$ for AZO films deposited at almost same sputtering parameters as reported by Guilléna and Herrero (2010). The carrier concentration is $2.3 \times$ $10^{20} \mathrm{~cm}^{-3}$ for the $153 \mathrm{~nm} \mathrm{AZO} \mathrm{film,} \mathrm{then,} \mathrm{increases} \mathrm{to}$ $7.7 \times 10^{20} \mathrm{~cm}^{-3}$ for the $1404 \mathrm{~nm}$ AZO film. It is noticeable that, for thinner AZO film, poor crystalline and large stress may exist in the AZO layer, which leads to lots of defects. Many free electrons then are caught by large numbers of traps formed by these defects. The Hall mobility increases from 5.3 to $8.4 \mathrm{~cm}^{2} \mathrm{~V}^{-1} \mathrm{~s}^{-1}$ with increasing film thickness, which is mainly due to the enhancement of the crystalline and grain size. This suggests that in polycrystalline AZO film, the mobility is mainly affected by the scattering associated with imperfections such as grain boundaries or dislocations. Therefore, the decreasing resistivity with increasing film thickness is attributed to the increase of carrier concentration and Hall mobility.

\subsection{Optical characteristics of AZO films}

Figure 10 shows transmittance (including substrate) of AZO films in visible range as a function of film thickness and the inset shows the bandgap. All AZO films are uniform and transparent under naked-eye observation. The average transmittance of AZO films exceeds $80 \%$ in the range of $400-900 \mathrm{~nm}$. With increasing film thickness, the transmittance slightly decreases because of thickness effect. Strong oscillations in transmittance curves are 
observed clearly in the range of $400-900 \mathrm{~nm}$, which is due to the constructive or destructive light interference at different wavelengths by multiple internal reflections between AZO/air and AZO/glass interfaces. The interference is more obvious for thicker AZO films. When thickness exceeds a certain value ( $\gtrsim 180 \mathrm{~nm})$, the interference ripples will occur in transmittance spectrum due to etalon interference effects produced between air/film and film/substrate interfaces (Manifacier et al 1976). The bandgap for direct interband transition is given by Ziegler et al (1981) as follows:

$$
\alpha h v=C\left(h v-E_{\mathrm{g}}\right)^{1 / 2},
$$

where $C$ is a constant, $\alpha$ the optical absorption coefficient. The photon energy at the point where $(\alpha h v)^{2}$ is zero is $E_{\mathrm{g}}$ and can be determined by extrapolation of the $(\alpha h v)^{2}$ vs $(h v)$ curve. With increasing film thickness, the bandgap in inset shows red-shifting because of thickness

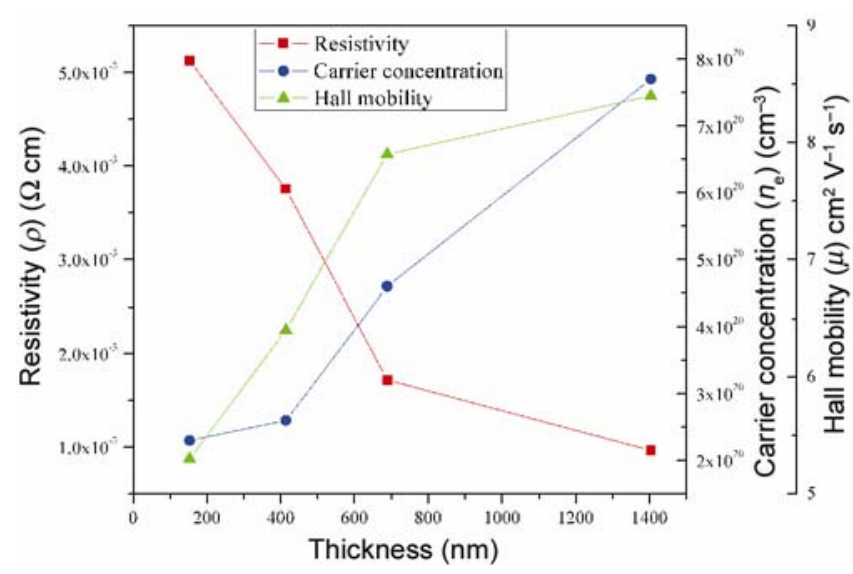

Figure 9. Resistivity, carrier concentration and Hall mobility of AZO films with different thicknesses.

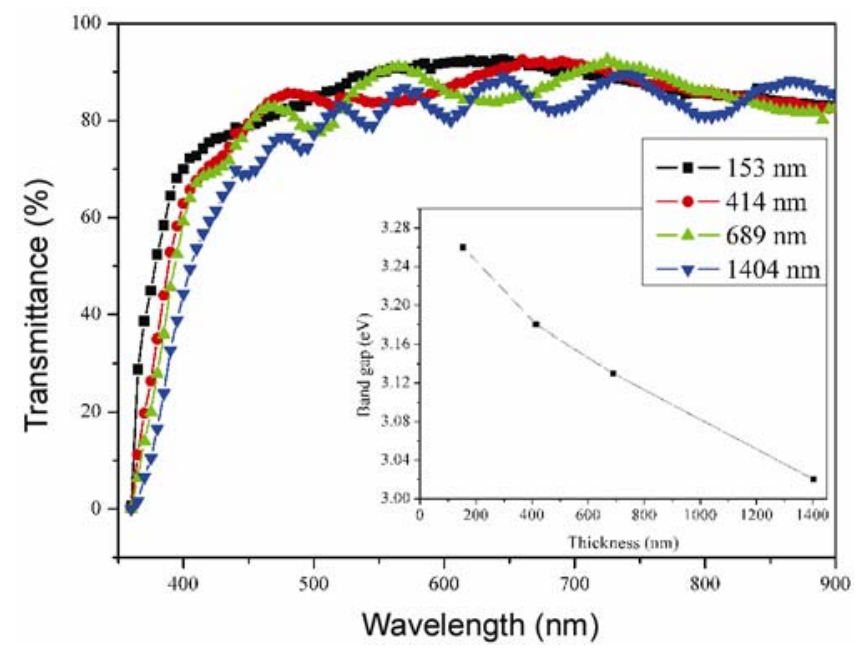

Figure 10. Transmittance of AZO films with different thicknesses in visible range and band gap (inset). effect. The bandgap decreases from 3.26 to $3.02 \mathrm{eV}$ with increase of film thickness from 153 to $1404 \mathrm{~nm}$, respectively.

\section{Conclusions}

AZO powders were synthesized by co-precipitation method and then AZO target was prepared using assynthesized powders. The powders are quasi-spherical with average diameter of $67 \mathrm{~nm}$. The target shows ultrahigh density of 99.3\% TD and low resistivity of $2 \mathrm{~m} \Omega \cdot \mathrm{cm}$. The phase structure of the AZO target is composed of 97\% $\mathrm{ZnO}$ (hexagonal) and $3 \% \mathrm{ZnAl}_{2} \mathrm{O}_{4}$ (cubic). $\mathrm{ZnAl}_{2} \mathrm{O}_{4}$ phase mainly distributes in $\mathrm{ZnO}$ grain boundaries. The eroded target surface is nodule and particle free. AZO films with different thicknesses deposited using ultrahigh density target show hexagonal structure and $c$-axis preferred orientation. The thickness increases from 153 to $1404 \mathrm{~nm}$, the grain size increases from 97 to $290 \mathrm{~nm}$, and the roughness increases from 0.34 to $10.54 \mathrm{~nm}$. The resistivity of AZO films decreases from $5.1 \times 10^{-3}$ to $9 \cdot 7 \times 10^{-4} \Omega \cdot \mathrm{cm}$. The transmittance of AZO films exceeds $80 \%$ in visible range and the bandgap in the range of 3.02-3.26 eV and shows small red-shifting.

\section{Acknowledgements}

This work is supported by the National Natural Science Foundation of China (61066001) and Guangxi National Science Foundation (2012GXNSFBA053168).

\section{References}

Chun B S, Wu H C, Abid M, Chu I C, Serrano-Guisan S, Shvets I V and Choi D S 2010 Appl. Phys. Lett. 97082109

Dewald W, Sittinger V, Werner W, Jacobs C and Szyszka B 2009 Thin Solid Films $\mathbf{5 1 8} 1085$

Guilléna C and Herrero J 2010 Vacuum 84924

Hélène S, Manuel G and Michel M 2009 Solid State Sci. 11 1192

Hsu C Y, Lin Y C, Kao L M and Lin Y C 2010 Mater. Chem. Phys. 124330

Ishibashi S, Higuchi Y, Ota Y and Nakamura K 1990 J. Vac. Sci. Technol. A8 1403

Kaelin M, Rudmann D and Tiwari A N 2004 Sol. Energy 77 749

Katayama M 1999 Thin Solid Films 341140

Kawada A 1990 Thin Solid Films 191297

Kima D W, Sung Y J, Park J W and Yeom G Y 2001 Thin Solid Films 398-399 87

Klutha O, Rech B, Houben L, Wieder S, Schöpe G, Beneking C, Wagner H, Löffl A and Schock H W 1999 Thin Solid Films 351247

Kuroyanagi A 1989 J. Appl. Phys. 665492

Lei B X, Liao J Y, Zhang R, Wang J, Su C Y and Kuang D B 2010 J. Phys. Chem. C114 15228 
Li C, Furuta M, Matsuda T, Hiramatsu T, Furuta H and Hirao T 2009 Thin Solid Films 5173265

Lodder J C, Wielinga T and Worst J 1983 Thin Solid Films 101 61

Long T, Zhu D and Wang L 2004 Electron. Comp. Mater. 23 31

Manifacier J C, Gasiot J and Fillard J P 1976 J. Phys. E: Sci. Instrum. 91002

Nadaud N, Nanot M and Boch P 1994 J. Am. Ceram. Soc. 77 843

Nakashima K and Kumahara Y 2002 Vacuum 66221

Omata T, Kita M, Okada H, Otsuka S, Matsuo Y, Ono N and Ikawa H 2006 Thin Solid Films 50322

Park J H, Ahn K J, Na S I and Kim H K 2011 Sol. Energy Mater. Sol. Cells 95657

Shirouzu K, Ohkusa T, Hotta M, Enomoto N and Hojo J 2007 J. Ceram. Soc. Japan 115254
Sittinger V, Dewald N, Werner W, Szyszka B and Ruske F 2009 Photovoltaics International 6101

Sun Y H, Xiong W H, Li C H and Yuan L 2009 J. Am. Ceram. Soc. 922168

Swann S 1998 Phys. Technol. 1967

Tak Y H, Kim K B, Park H G, Lee K H and Lee J R 2002 Thin Solid Films 41112

Tark S J, Kang M G, Park S, Lee S H, Son C S, Lee J C and Kim D 2011 Curr. Appl. Phys. 11362

Wang X, Bai X, Duan H, Shi Z, Sun J, Lu S and Huang S 2011 Trans. Nonferrous Met. Soc. China 211550

Zhang Y, Wang W, Tan R, Yang Y, Zhang X, Cui P and Song W 2012 Int. J. Appl. Ceram. Tech. 9374

Zhu B L, Wang J, Zhu S J, Wu J, Zeng D W and Xie C S 2012 Phys. Status Solidi A 2091251

Ziegler E, Heinrich A, Oppermann H and Stover G 1981 Phys. Status Solidi A 66635 